\title{
ERRATUM
}

Y. N. Lim $\cdot$ Ajay Rane $\cdot$ R. Muller

\section{An ambispective observational study in the safety and efficacy of posterior colporrhaphy with composite Vicryl-Prolene mesh}

Int Urogynecol J (2004) DOI 10.1007/s00192-004-1236-7

In this article, the authors inadvertently provided a misleading description of Vypro II mesh (Ethicon,
Germany). It is actually a type 3 mesh, a macroporous mesh with a microporous component. The authors may have, though unintentionally, given readers the impression that it is a $100 \%$ macroporous mesh.
The online version of the original article can be found at http:// dx.doi.org/10.1007/s00192-004-1236-7

Y. N. Lim · A. Rane $(\bowtie) \cdot$ R. Muller

James Cook University, Townsville,

Queensland, Australia

E-mail: Ajay_Rane@health.qld.gov.au

Y. N. Lim · A. Rane

Department of Urogynecology, Townsville Hospital,

PO Box 670, 4810 Townsville, Queensland, Australia

R. Muller

Epidemiology and Biostatistics, School of Public Health,

James Cook University, Townsville, Queensland, Australia 